\title{
CÁCH CHUYỄN DỊCH CÁC YẾU TỐ DANH HÓA ĐộNG TỪ TRONG TIẾNG NHậT SANG TIẾNG VIỆT
}

\author{
Trần Thị Minh Phương* \\ Khoa Ngôn ngũ và Văn hóa Nhật Bản, Truờng Đại học Ngoại ngũu, ĐHQGHN, \\ Phạm Văn Đồng, Cầu Giấy, Hà Nội, Việt Nam \\ Nhận bài ngày 09 tháng 06 năm 2017 \\ Chỉnh sửa ngày 08 tháng 09 năm 2017; Chấp nhận đăng ngày 28 tháng 09 năm 2017
}

Tóm tắt: Bài viết này đề cập đến cách chuyển dịch các yếu tố danh hóa (YTDH) động từ trong tiếng Nhật sang tiếng Việt. Kết quả khảo sát ngữ liệu trong 06 bản dịch truyện ngắn hiện đại của Nhật Bản cho thấy, khi chuyển dịch sang tiếng Việt đối với trường hợp danh hóa cho động từ, thì ở cả câu có vị ngữ danh từ, vị ngữ tính từ, vị ngữ động từ đều có những phương thức chuyển dịch giống nhau. Đó là: (i) YTDH trong tiểng Nhật được chuyển dịch bằng một YTDH tương đương trong tiếng Việt; (ii) YTDH trong tiếng Nhật được chuyển dịch bằng một danh từ khái quát; (iii) Tổ hợp “ Động tù + yếu tố danh hóa" trong câu tiếng Nhật được chuyển dịch bằng một danh từ. Danh từ này thường được phái sinh từ động từ xuất hiện trong tổ hợp đó; (iv) YTDH trong tiếng Nhật bị lược bỏ khi chuyển dịch. Trong các phương thức chuyển dịch này thì phương thức chuyển dịch (i) được sử dụng ít nhất. Tiếp đến là các phương thức chuyển dịch (ii) và (iii). Phương thức chuyển dịch (iv) được sử dụng nhiều nhất. Ngoài ra, các YTDH khi được chuyển dịch bằng một YTDH tương đương trong tiếng Việt thì YTDH được chọn đều là "việc", không thấy có sự xuất hiện của các YTDH nào khác.**

Tù khóa: yếu tố danh hóa động từ, "No", "Koto", phương thức chuyển dịch

\section{1. Đặt vấn đề}

Trong tiếng Nhật có tồn tại hiện tượng danh hoá và sự danh hóa được thực hiện chủ yếu bằng việc kết hợp động từ, tính từ hay mệnh đề với các yếu tố ngữ pháp chuyên dùng (Ojima, 1996; Kamada,1998; Tanaka, 1997). Yếu tố ngữ pháp chuyên dùng này thường được gọi là "yếu tố danh hóa (YTDH)". Trong đó, ngoài tên gọi "yếu tố danh hóa", những YTDH đứng sau tính từ, động từ để tạo ra từ phái sinh còn được gọi là "phụ tố" hay "tiếp vĩ từ”. Còn những YTDH đứng sau mệnh đề để tạo thành những tổ hợp danh từ tính thì ngoài cách gọi là "yếu tố danh hoá", chúng có thể còn được gọi là "danh từ hình thức" .

Hiện tượng danh hóa động từ trong tiếng Nhật được biểu thị bằng nhiều phương thức

\footnotetext{
* ĐT.: 84-913299099

Email: yuritran2008@gmail.com

** Nghiên cứu này được hoàn thành với sự hỗ trợ của Trường Đại học Ngoại ngữ, Đại học Quốc gia Hà Nội trong đề tài mã số N.16.21
}

khác nhau, nhưng trong bài viết này tôi chỉ đề cập đến phương thức kết hợp với yếu tố danh hóa "no"; "koto". "no" và "koto" là hai yếu tố danh hóa động từ phổ biến trong tiếng Nhật. Nó còn được gọi là yếu tố danh hóa mệnh đề. Người học tiếng Nhật thường hay gặp khó khăn và hay bị nhầm lẫn trong cách dùng của các yếu tố danh hóa này. Hiện nay chưa có nghiên cứu nào tiến hành đối chiếu các yếu tố danh hóa động từ trong tiếng Nhật với tiếng Việt. Chính vì vậy, để giúp cho sinh viên Việt Nam học tiếng Nhật có thể nắm bắt được cách dùng của các yếu tố danh hóa này, đồng thời giúp giảm thiểu những lỗi do ảnh hưởng bởi sự chuyển di tiêu cực của tiếng mẹ đẻ khi dùng. Nghiên cứu này tiến hành khảo sát các yếu tố danh hóa động từ lấy từ nguồn dữ liệu là các tác phẩm truyện ngắn, tiểu thuyết Nhật Bản có bản dịch sang tiếng Việt để tìm ra các phương thức chuyển dịch. Kết quả nghiên cứu khảo sát thu được 
sẽ góp phần cho việc giảng dạy tiếng Nhật và có giá trị tham khảo khi biên soạn giáo trình, tài liệu giảng dạy.

\section{Phương pháp, đối tượng và dữ liệu nghiên cứu}

\subsection{Phưong pháp nghiên cúu}

Nghiên cứu này áp dụng các phương pháp nghiên cứu như sau:

- Phương pháp so sánh - đối chiếu một chiều: Cụ thể sẽ chọn lọc ra những câu trong các tác phẩm tiểu thuyết, truyện ngắn của Nhật có sử dụng YTDH "no" và " $k o t o "$ rồi đối chiếu với đơn vị/ cách diễn đạt tương đương của chúng trong bản dịch tiếng Việt để tìm hiểu các YTDH trong tiếng Nhật được chuyển dịch sang tiếng Việt bằng những phương thức nào, trật tự trong câu chuyển dịch có bị thay đổi so với câu gốc tiếng Nhật hay không?... Từ đó có thể làm sáng tỏ thêm về ý nghĩa cũng như cách dùng của các YTDH giữa hai ngôn ngũ̃.

- Phương pháp thống kê: Giúp xác định tần số sử dụng của các YTDH để làm căn cứ cho các nhận xét mang tính chất định tính.

\section{2. Đối tượng nghiên cưu}

\subsection{1. Định nghĩa "Yếu tố danh hóa"}

Đối tượng nghiên cứu trong bài viết này được xác định là các yếu tố khi kết hợp với tính từ, cụm tính từ hay kết hợp với động từ, cụm động từ, hoặc mệnh đề thì có chức năng biến đổi các cụm kết hợp từ này thành danh từ hay danh ngữ. Tuy nhiên, những trường hợp định danh tựa danh hóa sau đây sẽ không thuộc phạm vi nghiên cứu của bài báo này. Đó là kiểu như danh hóa động từ để tạo ra danh từ chỉ kẻ hành động tương đương với những tổ hợp tiếng Việt như: "Ngườ $i$ nó $i=$ Người nói”... Hay danh hóa động từ để tạo ra danh từ chỉ sự vật có tính năng, công dụng do động từ đó biểu hiện, như: "Máy + bay = Máy bay”... (Nguyễn Thị Thuận, 2002).

\subsubsection{Tiêu chí nhận diện "Yếu tố danh hóa"}

Trong nghiên cứu này, đối tượng được gọi là "yếu tố danh hóa" có những đặc điểm cụ thể như sau:

- Là các yếu tố mà bản thân chúng không có nghĩa thực hoặc có hàm lượng nghĩa thực nhất định khi đứng độc lập một mình.

- Có khả năng kết hợp với tính từ, cụm tính từ, động từ, cụm động từ, mệnh đề để biến những tính từ, cụm tính từ, động từ, cụm động từ, mệnh đề đó thành danh từ và danh ngữ/ tổ hợp danh từ.

\subsection{Dũ liệu nghiên cứu}

Trong nghiên cứu này tôi tiến hành khảo sát một số tác phẩm truyện ngắn bằng tiếng Nhật đã được dịch và ấn hành bằng tiếng Việt để tìm hiểu YTDH động từ trong tiếng Nhật trên thực tế sử dụng ngôn ngữ được chuyển dịch sang tiếng Việt như thế nào. Trong nghiên cứu này, tôi tiến hành nghiên cứu theo kiểu nghiên cứu trường hợp bằng cách chọn hai YTDH điển hình " no" và " koto" làm đối tượng khảo sát bởi vì đây là hai YTDH mà người học tiếng Nhật hay bị nhầm lẫn và dùng sai nhiều nhất (Ichikawa, 1998: 98). Cụ thể, nghiên cứu này khảo sát xem:

- Có những phương thức chuyển dịch YTDH " no", " koto" nào sang tiếng Việt ?

- Các YTDH trong tiếng Nhật có được chuyển dịch bằng một YTDH tương đương trong tiếng Việt hay không ?

- Nếu có thì đó là YTDH nào và nếu không thì chúng được chuyển dịch bằng những biểu thức tương đương nào?

Khi tiến hành đối chiếu cách chuyển dịch YTDH " no", “ koto" trong tiếng Nhật với các đơn vị tương đương trong tiếng Việt tôi sử dụng nguồn dữ liệu là bản dịch Nhật - Việt của 06 tác phẩm truyện ngắn hiện đại của Nhật như sau: 
Bảng 1. Các tác phẩm truyện ngắn Nhật Bản

được đánh số theo số thứ tự ban đầu được sử dụng làm dữ liệu nghiên cứu tương ứng với câu gốc tiếng Nhật.

\begin{tabular}{|c|c|c|c|c|c|}
\hline STT & $\begin{array}{l}\text { Tên tác phẩm/ } \\
\text { Ký hiệu viết tắt }\end{array}$ & Tác giả & Năm/ Nhà xuất bản & $\begin{array}{l}\text { Bản dịch } \\
\text { tiếng Việt }\end{array}$ & Dịch giả \\
\hline 1 & 『リング』/ R & Suzuki Kouji & $\begin{array}{c}\text { 1991/Kadokawa } \\
\text { Shoten } \\
\end{array}$ & "Vòng tròn ác nghiệt" & \multirow{5}{*}{$\begin{array}{l}\text { Lương } \\
\text { Việt Dũng }\end{array}$} \\
\hline 2 & $\begin{array}{l}\text { 『ベッドタイム } \\
\text { ズ』/ B } \\
\end{array}$ & Yamada Eimi & 2000/Shincho Bunko & $\begin{array}{l}\text { "Đôi mắt ấy vẫn ở trên } \\
\text { giường" }\end{array}$ & \\
\hline 3 & $\begin{array}{c}\text { 『博士の愛 } \\
\text { した数式』 } \\
\text { (Hakase )/ H }\end{array}$ & Kogawa Yoko & 2003/ ShinchoSha & $\begin{array}{l}\text { "Giáo sư và công thức } \\
\text { toán" }\end{array}$ & \\
\hline 4 & $\begin{array}{c}\text { 『キッチン』/ } \\
\mathrm{K}\end{array}$ & $\begin{array}{l}\text { Yoshimoto } \\
\text { Banana }\end{array}$ & $\begin{array}{c}\text { 1998/Kadokawa } \\
\text { Bunko }\end{array}$ & "Kitchen (Nhà bếp)" & \\
\hline 5 & 『N P』/NP & $\begin{array}{l}\text { Yoshimoto } \\
\text { Banana }\end{array}$ & $\begin{array}{c}\text { 1990/Kadoka } \\
\text { wa Shoten }\end{array}$ & "NP" & \\
\hline 6 & $\begin{array}{c}\text { 『さような } \\
\text { ら、ギャング } \\
\text { たち』/S }\end{array}$ & $\begin{array}{l}\text { Takahashi } \\
\text { Genichiro }\end{array}$ & 2013/ Kodansha & "VĨnh biệt Gangster" & Mộc Miên \\
\hline
\end{tabular}

\subsection{Các bước thu thập dĩ liệu nghiên cưu}

Dữ liệu nghiên cứu được tiến hành theo các bước sau:

- Thu thập tất cả những câu có sử dụng YTDH “no", "koto" trong 06 tác phẩm truyện ngắn nói trên. Sau đó tư liệu được đánh số theo thứ tự tăng dần. Một số cấu trúc có sử dụng YTDH "no", "koto" như " $\sim$ koto ga dekiru / có thể; $\sim V t a+$ koto ga aru / đã tùng (kinh nghiệm); $\sim$ Vta + koto ga nai / chua tùng; koto ni naru/ koto ni suru/ quyết định", " no ni suru/ lưa chon "... được coi là những cụm từ cố định có cách dùng như quán ngũ̃ (慣用表現) (Tanaka, 1997: 176). Những cụm từ cố định này không được đưa vào đối tượng khảo sát. Ngoài ra, trường hợp "koto" được dùng ở mệnh đề phụ trong câu, như " koto de, " hay " koto ni, 〜" không thuộc đối tượng nghiên cứu. Câu có vị ngữ danh từ thuộc dạng câu nhấn mạnh (強調構 文) hay còn gọi là câu phân liệt (分裂 文) như “先週この本を駅の本屋で 買ったのは田中さんだ” cũng không thuộc đối tượng khảo sát.

- Tìm câu chuyển dịch tương đương trong bản dịch tiếng Việt đối với các câu đã thu thập được. Tư liệu cũng
- Nhập dữ liệu vào file excel: Để thuận tiện cho việc phân tích đối chiếu và muốn khảo sát xem thành phần vị ngữ trong câu có ảnh hưởng đến các phương thức chuyển dịch hay không tôi đã chia dữ liệu thành 3 nhóm. Đó là nhóm câu có vị ngữ là danh từ, nhóm câu có vị ngữ là tính từ, nhóm câu có vị ngữ là động từ. Bước tiếp theo là nhập đầy đủ các câu tiếng Việt đã được chuyển dịch tương ứng với câu gốc tiếng Nhật vào trong file. Ngoài ra, để thuận tiện cho quá trình trích dẫn và tra cứu sau này, tôi còn nhập cả thông tin nguồn trích dẫn của câu đó. Cụ thể là số thứ tự câu và tên tác phẩm được trích nguồn.

- Để làm nổi bật rõ sự chuyển dịch các YTDH trong tiếng Nhật sang tiếng Việt, khi trích dẫn các câu ví dụ tôi quy định như sau: Với những câu mà YTDH của tiếng Nhật được chuyển dịch tương đương bằng một $\mathrm{YTDH}$ trong tiếng Việt tôi sẽ không đưa ra câu đối dịch mà chỉ trích dẫn y nguyên câu chuyển dịch trong bản dịch, nhưng đối với những câu mà YTDH tiếng Nhật không được chuyển dịch bằng một YTDH tương đương mà được chuyển dịch bằng một biểu thức khác hoặc chúng bị lược bỏ thì tôi sẽ đưa ra câu 
đối dịch để thấy rõ hơn sự chuyển dịch giữa hai ngôn ngữ. Cụ thể như sau:

- Câu chữ in nghiêng: Là câu đối dịch với câu ví dụ của tiếng Nhật. Nghĩa là phần tiếng Nhật sẽ được đối dịch tương đương, với trường hợp trong câu xuất hiện những trợ từ không có cách dịch tương đương sang tiếng Việt, tôi ký hiệu bằng $(\mathrm{O})$, còn YTDH xuất hiện trong câu tôi ký hiệu bằng $(\boldsymbol{\Delta})$.

- Câu không in nghiêng: Là câu được chuyển dịch trong bản dịch. Phần gạch chân ở câu chuyển dịch biểu thị phần được chuyển dịch tương đương sang tiếng Việt từ YTDH trong tiếng Nhật. Còn trong câu chuyển dịch không có phần gạch chân biểu thị rằng YTDH trong câu tiếng Nhật đã bị mất đi hay nó được chuyển dịch bằng một cách nói khác khi dịch sang tiếng Việt. Ví dụ:

(1) a. ここに住むのは少女の私の 夢だった。(N: 224)

Đây/ở/sống/ \/O/con gái/củal tôi/của/giấc mo: (Câu đối dịch)

Được sống ở đây đã từng là mong ước của tôi thời con gái. (Câu chuyển dịch trong bản dịch)

(2)b. 父に好きな女性ができたの が原因だった。(N: 27)

Bố tôi/o/thích/người đàn bà/o/có thể/ $\mathbf{O} /$ /nguyên nhân. (Câu đối dịch)

Nguyên nhân là do bố tôi đem lòng yêu người đàn bà khác. (Câu chuyển dịch trong bản dịch)

\subsection{Tiêu chí phân nhóm ngũ liệu}

Ojima chỉ ra rằng trong tiếng Nhật thành phần vị ngữ có vai trò quyết định cho việc dùng yếu tố danh hóa "No" hay "Koto". Nói cách khác, tùy theo đặc điểm của thành phần vị ngữ kết hợp là như thế nào sẽ quyết định việc sử dụng yếu tố danh hóa "No" hay "Koto" (Ojima, 1996: 55). Vì vậy khi phân nhóm dữ liệu ngoài mục đích để thuận tiện cho việc đối chiếu, tôi muốn khảo sát xem khi chuyển dịch sang tiếng Việt, đặc điểm của thành phần vị ngữ trong câu có ảnh hưởng đến các phương thức chuyển dịch hay không? Do đó, tôi đã chia dữ liệu nghiên cứu thành 3 nhóm như sau:

- Đối với câu có sử dụng YTDH "no": Phân nhóm như dưới đây:

+ “ no" trong câu có vị ngữ là danh từ. Ví dụ:

(3) 詩を教えるのは恥ずかしくない仕事 だ (S:8)

Tho\%/dạy/ム/o/không xấu hổ/công việc.

Dav thơ có gì đáng xấu hổ đâu.

+ “ no" trong câu có vị ngữ là tính từ. Ví dụ:

（4）直子の部屋を見つけるのは簡単だ つた。

Việc tìm phòng của Naoko thật đơn giản.

+ “no" trong câu có vị ngữ là động từ. Ví dụ:

(5) 僕は直子が泣き止むのを待った。

Tôi chờ Naoko ngù̀ng khóc.

- Đối với câu có sử dụng YTDH “koto”: Phân loại theo tiêu chí cụ thể như sau:

+ “ koto" trong câu vị ngữ là danh từ. Ví dụ:

（6）ここを出て行くことは完全にその人 の自由だ。

Việc đi khỏi đây hoàn toàn là quyền tự do của người đó.

+ “ koto" trong câu vị ngữ là tính từ. Ví dụ:

(7) 彼女が僕のもとに戻ってくれたこと はとても嬉しかつた。

Việc cố ấy quay trở lai bên canh tôi làm tôi rất vui.

+ “ koto" trong câu vị ngữ là động từ. Ví dụ:

(8) 色々な思いが彼女の頭の中でぐる ぐると回っていることが分った。

Tôi biết việc hiện nay trong đầu cô ấy đang vẩn vơ nhiều suy nghĩ.

+ Tổ hợp " Động từ/ tính từ + koto" làm vị ngữ trong câu. Ví dụ:

(9) それはちやんと考えて決めたこと たシ。

Đó là một sự quyết định hoàn toàn có suy nghĩ chín chắn. 
3. Kết quả khảo sát cách chuyển dịch yếu tố danh hóa động từ "No", "Koto" trong tiếng Nhật sang tiếng Việt

Kết quả khảo sát thu được như sau:

Bảng 4. Kết quả thống kê số lượng câu có vị ngữ là danh từ có sử dụng "no"

\begin{tabular}{|c|c|c|c|c|c|c|}
\hline \multicolumn{6}{|c|}{ Tên tác phẩm truyện ngắn } & \multirow{2}{*}{ Tổng cộng } \\
\hline $\mathbf{R}$ & B & $\mathbf{H}$ & $\mathbf{K}$ & NP & $\mathbf{S}$ & \\
\hline $75(33 \%)$ & $96(42,2 \%)$ & $25(11,0 \%)$ & $3(1,32 \%)$ & $15(6,6 \%)$ & $13(5,7 \%)$ & $227(100 \%)$ \\
\hline
\end{tabular}

3.1. Kết quả khảo sát cách chuyển dịch YTDH "no" sang tiếng Việt

Đối với câu có sử dụng YTDH “ no", tôi thu được kết quả thống kê như sau:
Qua quá trình phân tích dũ̃ liệu, tôi đã phân ra một số phương thức chuyển dịch của "no" hay danh từ vốn được danh hóa từ động từ bằng " no" sang tiếng Việt như sau:

Bảng 2. Kết quả thống kê số lượng câu có sử dụng YTDH "no"

\begin{tabular}{|c|c|c|c|c|c|c|c|}
\hline \multirow{2}{*}{ Vị trí của “ no" } & \multicolumn{6}{|c|}{ Tên các tác phẩm truyện ngắn } & \multirow{2}{*}{ Tổng cộng } \\
\cline { 2 - 7 } & $\mathbf{R}$ & $\mathbf{H}$ & $\mathbf{K}$ & $\mathbf{B}$ & $\mathbf{N P}$ & $\mathbf{S}$ & \\
\hline $\begin{array}{c}\text { "No" trong câu có } \\
\text { vị ngữ là DT }\end{array}$ & 75 & 25 & 3 & 96 & 15 & 13 & $\begin{array}{c}227 \\
(36,6 \%)\end{array}$ \\
\hline $\begin{array}{c}\text { "No" trong câu có } \\
\text { vị ngữ là TT }\end{array}$ & 11 & 54 & 23 & 8 & 20 & 7 & $\begin{array}{c}123 \\
(19,8 \%)\end{array}$ \\
\hline $\begin{array}{c}\text { "No" trong câu có } \\
\text { vị ngữ là ĐT }\end{array}$ & 46 & 107 & 46 & 21 & 41 & 9 & $\begin{array}{c}270 \\
(43,5 \%)\end{array}$ \\
\hline Tổng & $\begin{array}{c}132 \\
(21,2 \%)\end{array}$ & $\begin{array}{c}186 \\
(30 \%)\end{array}$ & $\begin{array}{c}72 \\
(11,6 \%)\end{array}$ & $\begin{array}{c}125 \\
(20,1 \%)\end{array}$ & $\begin{array}{c}76 \\
(12,49 \%)\end{array}$ & $\begin{array}{c}29 \\
(4,67 \%)\end{array}$ & $\begin{array}{c}\mathbf{6 2 0} \\
(100 \%)\end{array}$ \\
\hline
\end{tabular}

\subsubsection{Cách chuyển dịch "no" trong câu có vị} ngũ là danh tù

Câu có vị ngữ là danh từ (danh từ hay cụm danh từ/ danh ngữ) là những câu có thành phần vị ngữ là "hệ từ LÀ + danh từ hoặc cụm danh từ”. Trong tiếng Nhật, cấu trúc câu sẽ là “A は B だ”. Cả $A$ và $B$ đều phải là danh từ $(\mathrm{N})$ hoặc cụm danh từ (NP). Trong tiếng Việt, tương đương với cấu trúc câu này là "A là B" (Nguyễn Thị Lương, 2006). Tuy nhiên, do trong tiếng Việt "động từ/ cụm động từ (VP)" có thể làm chủ ngữ trong câu nên không nhất thiết $\mathrm{A}$ phải là $\mathrm{N}$ hoặc $\mathrm{NP}$. Sự khác nhau về cấu trúc của câu trong tiếng Nhật và tiếng Việt được thể hiện ở bảng sau:

Bảng 3. So sánh cấu trúc câu có vị ngữ là danh từ trong tiếng Nhật và tiếng Việt

\begin{tabular}{|c|c|c|}
\hline & Tiếng Nhật & Tiếng Việt \\
\hline Cấu trúc câu & $\sim \mathrm{A}$ は $\sim$ だ。 & $\mathrm{A}$ là $\mathrm{B}$. \\
\hline $\begin{array}{c}\text { Thành phần } \\
\text { cấu tạo }\end{array}$ & $\mathrm{NP}$ はN & $\mathrm{NP} / \mathrm{VP}$ là NP. \\
\hline
\end{tabular}

- PTCD 1: YTDH “no” được chuyển dịch bằng một YTDH tuoong đurong trong tiếng Việt

(10) 自分がやった影響を過小評価するの は数学者全般に見られる傾向なのだろう。 (H: 516)

Viêc tự đánh giá thấp ảnh hưởng của những gì mà mình đã làm được là khuynh hướng chung của tất cả các nhà toán học.

(11) 泊まった旦は事実だ。(H: 353)

Viêcc cô ngủ lại đó là sự thật.

Ở các ví dụ từ (10) đến (11) ta thấy YTDH “no" trong câu tiếng Nhật được đối dịch bằng một YTDH tương đương trong tiếng Việt là "việc". YTDH trong tiếng Việt được dùng để chuyển dịch cụm danh hóa bằng "no" chỉ có "việc", không thấy sự xuất hiện của các YTDH khác.

- PTCD 2: YTDH "no" được chuyển dịch bằng môt danh tù độc lập 
Ở phương thức chuyển dịch này, YTDH "no" được chuyển dịch sang tiếng Việt bằng một danh từ độc lập. Chúng ta hãy xem xét các ví dụ sau đây:

(12)「「いただきます」と言ってくれ たのは息子と三人で取った最初の夕食の 席だった。(H: 78)

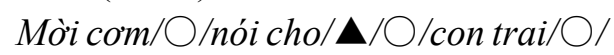
ba ngươillấy/lần đầu/○bũa tối/○/ghế.

Lần đầu giáo sư chắp hai tay mời cơm cũng là lần đầu tiên ba chúng tôi cùng ăn bữa tối.

(13) 抽象的な質問からスタートする のが博士のスタイルだった。

Trùu tượng/câu hỏi/o/bắt đầu/A/o/ giáo su/o/phong cách.

Kiểu bắt đầu từ những câu hỏi trừu tượng là cách của giáo sư.
Khác với những câu thuộc phương thức chuyển dịch 2 có sử dụng một danh từ khái quát để thay thế cho "no" nhằm nhấn mạnh và làm rõ thành phần "tiền đề" trong câu, ở các ví dụ từ (14) (15), ta thấy thành phần kết hợp đứng trước "no" là một mệnh đề. Khi chuyển dịch sang tiếng Việt, YTDH "no" đã bị mất đi, hoàn toàn không có dấu hiệu của yếu tố được thay thế tương đương.

\subsubsection{Cách chuyển dịch "no" trong câu} có vị ngũu là tính tù

Kết quả thống kê các câu có sử dụng YTDH "no" trong câu có vị ngữ là tính từ được chuyển dịch sang tiếng Việt như sau:

Bảng 5 . Kết quả thống kê số câu có vị ngữ là tính từ có sử dụng "no"

\begin{tabular}{|c|c|c|c|c|c|c|}
\hline $\mathbf{R}$ & $\mathbf{B}$ & $\mathbf{H}$ & $\mathbf{K}$ & $\mathbf{N P}$ & $\mathbf{S}$ & Tổng cộng \\
\hline $11(8,9 \%)$ & $8(6,5 \%)$ & $54(43,9 \%)$ & $23(18,6 \%)$ & $20(16,2,3 \%)$ & $7(5,7 \%)$ & $\mathbf{1 2 3}(\mathbf{1 0 0} \%)$ \\
\hline
\end{tabular}

Ở ví dụ (12) (13) trên đây, ta thấy YTDH "no" được chuyển dịch sang tiếng Việt bằng các từ ngữ danh từ tính "lần đầu" "kiểu".

- PTCD 3: YTDH “no" bị lược bỏ. Trật tụ câu được giũ nguyên hoạc bị thay đổi khi chuyển dịch

Trong phương thức chuyển dịch 3 này, qua quá trình khảo sát tư liệu, tôi thấy rằng khi chuyển dịch sang tiếng Việt, YTDH "no" đã bị lược bỏ. Trật tự câu khi đó được giữ nguyên theo câu gốc tiếng Nhật hoặc được đảo lại trật tự cho phù hợp với văn phong tiếng Việt. Xét các ví dụ dưới đây:

(14) 父に好きな女性ができたのが原 因だった。(N: 27)

Bố tôi/O/thích/người đàn bà/○/có thể/ $\mathbf{\Delta} / \bigcirc /$ nguyên nhân.

Nguyên nhân là do bố tôi đem lòng yêu người đàn bà khác.

(15) 彼に弟の話を聞いたのは初めて だった。(K: 309)

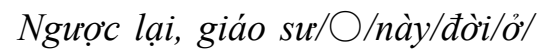
nhất/ghét/ム/O/đông người.

Ngược lại giáo sư ghét nhất chỗ đông người.
Trong số các câu có vị ngữ là tính từ, tôi chia thành hai nhóm chính. Đó là nhóm tính từ biểu thị trạng thái, tính chất, sự đánh giá như: khó, thú vị, đơn giản, tiện lơi... và nhóm tính từ biểu hiện trạng thái tâm lý - tình cảm của con người như: thich, ghét, sợ...

a. Câu có vị ngũ̃ là tính tù biểu thị trạng thái, tính chất, sụ đánh giá

Đối với câu có vị ngữ là tính từ biểu thị trạng thái, tính chất, sự đánh giá, tôi khảo sát và thu được các phương thức chuyển dịch như sau:

- PTCD 1: YTDH “no” đurợc chuyển dịch bằng một YTDH tuơng đuoong trong tiếng Việt

Phương thức chuyển dịch này có tỉ lệ sử dụng rất ít. Chỉ có 03 câu, chiếm 2,6\% trong tổng số 123 câu. Xét các ví dụ dưới đây:

(16) 彼らの出現を一定の規則によっ て予言する旦は不可能である。

(H: 185)

Việc dự đoán sự xuất hiện của chúng dựa vào một quy luật là bất khả.

(17) 10を底にする対数を用いるのが 便利だ。(H: 424) 
Việc sử dụng Logarit với cơ số 10 rất tiện lọi.

Ở ví dụ (16), (17) YTDH “no" được chuyển dịch bằng YTDH "việc" trong tiếng Việt. "Việc" ở đây được sử dụng để danh hóa cho động từ "dự đoán", "sử dụng” . Những động từ này đều là động từ hành động. Vì vậy ở đây "việc" không đóng vai trò là một danh từ khái quát mà đóng vai trò của một yếu tố danh hóa.

- PTCD 2: YTDH “no" được chuyển dịch bằng một danh tù khái quát

Cũng giống với câu có vị ngữ là danh từ, YTDH “no" cũng được chuyển dịch bằng một danh từ khái quát, nhưng số lượng câu không nhiều như câu có vị ngữ là danh từ. Kết quả khảo sát cho thấy, chỉ có 03 câu trong tổng số 123 câu có YTDH "no" được chuyển dịch bằng một danh từ khái quát. Xét các ví dụ sau:

(18) いずれにせよ、私の体にはスプ ーンという刻印が押されている旦は確か だ。(B: 74)

Nhưng nói gì thì nói, chuvên con dấu có cái tên Spoon đã đóng lên cơ thể tôi là điều không thể chối cãi.

Ở ví dụ (18) YTDH “no" được chuyển dịch bằng một danh từ khái quát "chuyện" . "Chuyện" ở đây biểu thị "sự việc", cụm động từ hay mệnh đề đứng sau "chuyện" có chức năng bổ sung ý nghĩa để cụ thể hóa cho "sự việc" được đề cập đến trong câu. Vì vậy, tổ hợp "chuyện + cụm động từ/ mệnh đề" là tổ hợp của "danh từ + định ngũ̃/ mệnh đề định ngữ".

- PTCD 3: YTDH “no" bi luợc bỏ đi. Tính tù làm vị ngũ trong câu được chuyển thành danh tì. Trật tự thành phần trong câu có thể vẫn giữ nguyên hoạc bị thay đồi

Ngoài phương thức chuyển dịch $1 \& 2$, phương thức chuyển dịch 3 cho thấy khi dịch sang tiếng Việt, YTDH “no" đã bị lược bỏ. Khi đó tính từ làm vị ngữ trong câu có sự biển đổi về mặt từ loại. Cụ thể là nó được biến đổi thành danh từ. Ví dụ:

(19) ルートはのけ者の数を見つける のが得意だった。(H: 187)
Căn/O/di chất/O/con số/○/tìm

ra/ム/giỏi.

Phát hiện ra những con số dị chất là sở trường của Căn.

Ta thấy ở các ví dụ (19) tính từ làm vị ngữ trong câu được chuyển thành danh từ khi chuyển dịch sang tiếng Việt. Cụ thể tính từ "Tokui/ giỏi, thành thạo" đã được chuyển thành danh từ "sở trương".

- PTCD 4: YTDH “no" bi luoơc bỏ, tính tù làm vị ngũ trong câu được biểu thị bằng một biểu thức tuoong đương khác

Ở phương thức chuyển dịch này, YTDH "no" bị lược bỏ, đồng thời tính từ làm vị ngữ trong câu tiếng Nhật được chuyển dịch bằng một biểu thức tương đương về nghĩa. Cụ thể như sau:

(20) 私の存在を覚えられないのは間 違いないようだった。(H: 63)

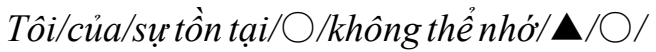
chắc chắn/hình nhur.

Giáo sư vẫn không nhớ được sự tồn tại của tôi.

Ở ví dụ (20), ta thấy trong câu chuyển dịch không hề thấy có dấu hiệu của YTDH "no" và tính từ làm vị ngữ trong câu được chuyển dịch bằng một biểu thức tương đương khác và vẫn giữ nguyên được ý của câu gốc tiếng Nhật. Trong ví dụ trên, ta thấy tính từ “間違いない chính xác, đúng, không sai" xuất hiện nhiều nhất. Điều này có thể cho ta thấy có khả năng tính từ này khi chuyển dịch sang tiếng Việt sẽ không còn nghĩa gốc của tính từ nữa mà được thay thế bằng một biểu thức tương đương với nghĩa của tính từ này.

- PTCD 5: YTDH “no” bi luợc bỏ, tính tù trong câu gốc tiếng Nhật vẫn được giũ nguyên. Trật tụ câu được giũ nguyên hoạc thay đổi

Khi chuyển dịch sang tiếng Việt, YTDH bị mất đi. Tính từ trong câu gốc tiếng Nhật vẫn được giữ nguyên. Trật tự câu chuyển dịch có thể được giữ nguyên hoặc thay đổi. Xét các ví dụ sau:

(21) 八十分の記憶について具体的な イメージを持つのは難しかった。(H: 18) 
Tám muơi/phút/của/ký úc/vè̀/cu thể/tưởng

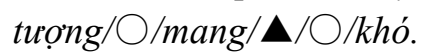

Thật khó cho tôi để hình dung ra một trí nhớ dài tám mươi phút thì sẽ như thế nào.

Ở ví dụ trên đây khi chuyển dịch sang tiếng Việt, YTDH "no" đã bị mất đi. Tính từ trong câu gốc tiếng Nhật vẫn được giữ nguyên.
3.1.3. Cách chuyển dịch "no" trong câu có vị ngứ là động tù

Đối với cách chuyển dịch YTDH "no" trong câu có vị ngữ là động từ, kết quả khảo sát thu được như sau:

Bảng 6. Kết quả thống kê số câu có vị ngữ là động từ có sử dụng "no"

\begin{tabular}{|c|c|c|c|c|c|c|}
\hline \multicolumn{6}{|c|}{ Tên các tác phẩm truyện ngắn } & \multirow{2}{*}{ Tổng cộng } \\
\hline $\mathbf{R}$ & B & $\mathbf{H}$ & K & NP & $\mathbf{S}$ & \\
\hline $46(17 \%)$ & $21(7,7 \%)$ & $107(39,6 \%)$ & $46(17 \%)$ & $41(15,1 \%)$ & $9(3,3 \%)$ & $270(100 \%)$ \\
\hline
\end{tabular}

\section{b. Câu có vị ngũ̃ là tính tù biểu thị tâm} lý - tình cảm của con nguời

Đối với câu có vị ngữ là tính từ biểu thị tâm lý - tình cảm của con người, có phương thức chuyển dịch như sau:

(22) 引越しはがきを書く五は本当に すごく好きなの。(K: 58)

\section{Chuyển nhà/buu thiếp/ $\bigcirc / v i e ̂ ́ t /$}

thật sụ/rất/thich. chuyển nhà.

Thực ra mình rất thích viết thiệp báo

$$
\text { w。(S: 55) }
$$

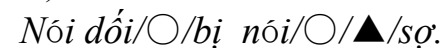

Tôi sợ bị nói là "Đồ điêu toa".

Tính từ xuất hiện trong câu có vị ngữ là tính từ biểu thị tâm lý - tình cảm của con người chủ yếu là: thích, sợ... Trong các ví dụ (22), (23), ta thấy khi chuyển dịch sang tiếng Việt, YTDH "no" đã bị lược bỏ. Tính từ làm vị ngữ trong câu đã biến đổi thành động từ trong câu chuyển dịch. Điều này là do sự khác nhau về mặt từ loại giữa tiếng Nhật và tiếng Việt. Vấn đề này cũng đã được đề cập ở phần câu có vị ngữ là danh từ. Trong tiếng Nhật “すき/ thich”, “い や/ ghét”, “怖い / sợ” về mặt từ loại là tính từ chỉ trạng thái, nhưng trong tiếng Việt "yêu", "ghét" "sợ" lại là vị từ chỉ các hoạt động tâm lý - tình cảm của con người. Chính vì vậy, tính từ trong câu gốc được chuyển thành câu vị ngữ động từ.
Qua quá trình khảo sát, phân tích đối chiếu, kết quả thu được như sau:

- PTCD 1: YTDH "no" được chuyển dịch bằng một YTDH tuoong duơng trong tiếng Việt

Phương thức này có tỉ lệ số câu sử dụng rất ít. Chỉ có 5 câu trong tổng số 270 câu, chiếm 1,85\%. Cụ thể như sau:

(24) 髪がくしゃくしゃになる旦を構 わず。(H:2)

Không hề để ý tới việc tóc nó sẽ rối tung lên.

Ở các ví dụ trên YTDH "no" trong câu tiếng Nhật được chuyển dịch bằng YTDH "việc" trong tiếng Việt. Vai trò của "việc" ở đây là tạo ra một tổ hợp danh từ có chức năng định danh.

- PTCD 2: YTDH "no" được chuyển dịch bằng một danh tù khái quát. Trật tụ thành phần câu khi chuyển dịch có thay đổ $i$

Theo phương thức chuyển dịch này, YTDH “no" được chuyển dịch bằng một danh từ khái quát. Số câu thuộc phương thức chuyển dịch 2 thu được cũng không nhiều. Chỉ có 8 câu, chiếm $3,1 \%$. Các danh từ khái quát chuyển dịch “no” được thống kê trong bảng sau:

Bảng 7. Danh từ khái quát để chuyển dịch "no" trong câu có vị ngữ động từ.

\begin{tabular}{|c|c|c|c|c|c|}
\hline $\begin{array}{c}R \\
\text { (4 câu) }\end{array}$ & $\begin{array}{c}\text { H } \\
\text { (3 câu) }\end{array}$ & $\begin{array}{c}\text { K } \\
\text { (1 câu) }\end{array}$ & $\begin{array}{c}\text { B } \\
\text { (0 câu) }\end{array}$ & $\begin{array}{c}\text { NP } \\
(0 \text { câu) }\end{array}$ & $\begin{array}{c}\text { S } \\
\text { (0 câu) }\end{array}$ \\
\hline khi (2), thứ, lúc & diều (2), thú & điều & & & \\
\hline
\end{tabular}


Xét các ví dụ cụ thể dưới đây:

(25)＼cjkstart博士が言っていたのを思い出 す。(H: 360)

Giáo su/o/nói///o/nhó'.

Tôi nhớ lại điều giáo sư từng nói.

Trong ví dụ (25) , YTDH “no” được chuyển dịch bằng một danh từ khái quát, đó là: "điều", danh từ khái quát để chỉ từng đơn vị của lời nói.

- PTCD 3: YTDH “no” bi luợc bỏ. Tổ hợp “ động tù + No” bị biến đổi thành danh tù bằng cách thêm các phụ tố khác. Trật tụ thành phần trong câu được giũ nguyên hoặc thay đổi.

Đối với phương thức chuyển dịch này, YTDH "no" hoàn toàn bị mất đi và có hiện tượng chuyển loại về từ vựng. Cụ thể là động từ đứng trước "no" đã bị biến đổi thành danh từ bằng cách kết hợp với các yếu tố khác. Trật tự thành phần trong câu tiếng Nhật được giữ nguyên hoặc thay đổi khi chuyển dịch sang tiếng Việt.

(26) トラックの運転手が男女が死んだ のを見つけ、警察署に通報した。(R: 86)
Chăm chú/nghĩ/tiếp tục/tôi/với/con trai/cuia/mạt $/ \bigcirc /$ nhìn/ $\mathbf{\Delta} / \bigcirc /$ không gì bằng/thich.

Trong ví dụ trên đây, chúng ta thấy YTDH "no" không có yếu tố tương đương trong câu chuyển dịch. Nói cách khác, "no" không được dịch bằng một yếu tố nào khác. Trật tự thành phần trong câu tiếng Nhật được chuyển dịch theo đúng cấu trúc câu tiếng Việt.

Tư liệu khảo sát cho thấy loại câu vị ngữ động từ có cấu trúc " V $+\mathrm{No}+\mathrm{Ni}+\mathrm{V} \sim$ " dùng để chỉ mục đích được sử dụng khá nhiều. Ví dụ:

（28）決定的な共通点を発見する四に そう時間はかからないだろう。 (R: 88)

Để tìm ra nó chắc sẽ không mất nhiều thời gian đến vậy.

3.2. Kết quả khảo sát cách chuyển dịch yếu tố danh hoá "koto"sang tiếng Việt

Kết quả thống kê số lượng câu có sử dụng YTDH "koto" thu được như sau:

Bảng 8. Kết quả thống kê số lượng câu có sử dụng YTDH "koto"

\begin{tabular}{|c|c|c|c|c|c|c|c|}
\hline \multirow[b]{2}{*}{ Vị trí của "koto" } & \multicolumn{6}{|c|}{ Tên các tác phẩm truyện ngắn } & \multirow[b]{2}{*}{ Tổng cộng } \\
\hline & $\mathbf{R}$ & $\mathbf{H}$ & $\mathbf{K}$ & B & NP & $\mathbf{S}$ & \\
\hline trong câu có vị ngữ là DT & 2 & 9 & 5 & 3 & 0 & 3 & $22(3,9 \%)$ \\
\hline trong câu có vị ngữ là TT & 17 & 11 & 8 & 0 & 4 & 2 & $42(7,5 \%)$ \\
\hline trong câu có vị ngữ là ĐT & 117 & 49 & 91 & 43 & 63 & 28 & $391(69,6 \%)$ \\
\hline $\begin{array}{l}\text { Tổ hợp "động từ / tính từ + } \\
\text { koto" làm vị ngữ trong câu }\end{array}$ & 31 & 25 & 26 & 7 & 12 & 5 & $\begin{array}{c}106(18,8 \\
\%)\end{array}$ \\
\hline Tổng & $\begin{array}{c}167 \\
(29,7 \%)\end{array}$ & $\begin{array}{c}94 \\
(16,7 \%) \\
\end{array}$ & \begin{tabular}{|c|}
130 \\
$(23,1 \%)$
\end{tabular} & $\begin{array}{c}53 \\
(9,4 \%)\end{array}$ & $\begin{array}{c}79 \\
(14 \%)\end{array}$ & $\begin{array}{c}38 \\
(6,7 \%)\end{array}$ & $\begin{array}{c}561 \\
(100 \%)\end{array}$ \\
\hline
\end{tabular}

Xe tải/của/người lái xe/o/đôi nam nũ̃) chết/வ/o/tìm thấy/cảnh sát/báo.

Một người lái xe tải hạng nhẹ đã tìm thấy xác chết của một đôi nam nữ và đã báo cho cảnh sát.

- PTCD 4: YTDH “no” bị luoơc bỏ. Trật tụ thành phần câu khi chuyển dịch có sụ thay đổi.

(27) じっと考え続ける私と息子の顔を 見つめるのをなによりも愛した。(H: 8)

\subsubsection{Cách chuyển dịch "koto" trong câu} có vị ngũ là danh tù̀

Số trường hợp "koto" trong câu có vị ngữ là danh từ không nhiều. Tổng số chỉ có 22 câu, trong đó có 01 câu "koto" danh hóa cho tính từ, còn lại đều danh hóa cho động từ. Cụ thể như sau: 
Bảng 9. Kết quả thống kê số câu có vị ngữ là danh từ có sử dụng "koto"

Mong muốn duy nhất của ông là tôi đừng có làm gì hết.

\begin{tabular}{|c|c|c|c|c|c|c|}
\hline $\mathbf{R}$ & $\mathbf{H}$ & $\mathbf{K}$ & $\mathbf{B}$ & $\mathbf{N P}$ & $\mathbf{S}$ & Tổng cộng \\
\hline 2 & 9 & 5 & 3 & 0 & 3 & 22 \\
\hline
\end{tabular}

Các phương thức chuyển dịch "koto" trong câu có vị ngữ là danh từ như sau:

- PTCD 1: YTDH "koto" được chuyển dịch bằng một YTDH tuoong đương trong tiếng Việt

(29) そんな女の子の相談にのることは 私の仕事だ。(S: 52)

Việc trò chuyện với những cô bé như thế này cũng là một phần công việc của tôi.

(30) 同じ部屋で生活していたことも全 て遠い夢のようです。

Việc sống chung một căn phòng đều giống như một giấc mơ diệu vợi.

Trong các ví dụ trên chúng ta thấy, YTDH "koto" trong câu tiếng Nhật được chuyển dịch bằng một YTDH tương đương trong tiếng Việt là "việc". "Việc" ở đây danh hóa cho động từ và cho mệnh đề có vai trò tạo nên tổ hợp danh từ.

- PTCD 2: YTDH "koto" được chuyển dịch bằng một danh tù̀ khái quát

(31) 博士の言っていることは本当だっ た。(H: 56)

Những điều giáo sư nói là sự thật.

(32) 気になり続けていることが一つだ けあった。(B: 130)

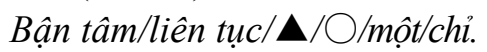

Có một chuvên luôn khiến tôi phải bận tâm.

Ở các ví dụ (31), (32) ta thấy YTDH "koto" được chuyển dịch bằng một danh từ khái quát trong tiếng Việt.

- PTCD 3: YTDH "koto" bi luợc bỏ. Trật tư thành phần trong câu bi thay đổi hoặc vẫn giũ nguyên
Trong ví dụ trên YTDH “koto” bị lược bỏ và thành phần trong câu chuyển dịch có sự thay đổi so với câu gốc tiếng Nhật.

- PTCD 4: YTDH "koto" bị luợc bỏ. Tổ hợp " động tù + koto" được chuyển dịch bằng môt danh tù chuyển loại tùt động tù trong tổ hợp đứng trước "koto"

(34) 理屈ではうまく説明できない が、言うことも顔つきも竜司ではなかっ た。(R: 805)

\section{Lý lẽ/○/trôi trảy/giải thích/không}

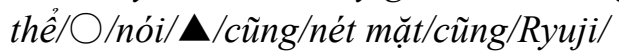
không phải là.

Gã không thể giải thích được một cách đầy đủ lý lẽ nhưng cả lời nói và nét mặt hắn đều không phải là Ryuji.

Trong ví dụ trên đây, danh từ "lời nói” đã được dùng để dịch tổ hợp "nói + koto" sang tiếng Việt. YTDH "koto" không được dịch bằng một $\mathrm{YTDH}$ tương đương, nhưng thay vào đó tổ hợp "động từ + koto" được chuyển sang thành danh từ. Danh từ này được phái sinh từ động từ nằm trong tổ hợp đó.

\subsubsection{Cách chuyển dịch "koto" trong câu có} vi ngũu là tính tù̀

Theo thống kê, số câu có vị ngữ tính từ tổng cộng là 40 câu. Số lượng câu thu thập được trong từng tác phẩm cụ thể như sau:

Bảng 10. Kết quả thống kê số câu có vị ngữ là tính từ có sử dụng "koto"

\begin{tabular}{|c|c|c|c|c|c|c|}
\hline $\mathbf{R}$ & $\mathbf{H}$ & $\mathbf{K}$ & $\mathbf{B}$ & $\mathbf{N P}$ & $\mathbf{S}$ & Tổng cộng \\
\hline 17 & 11 & 8 & 0 & 4 & 2 & 42 \\
\hline
\end{tabular}

(33) 何もしないでいてくれることが 一番の望みである。(H: 27)

Không làm gi// $\mathbf{\Delta} \bigcirc /$ nhất/mong muốn.
Trong số 42 câu thu thập được, các tính từ phần lớn là những tính từ biểu thị trạng thái, tính chất, sự đánh giá. Tính từ biểu thị tâm lý - 
tình cảm của con người chiếm số ít, chỉ có 07 câu trong tổng số 42 câu.

Các câu có vị ngữ là tính từ có những phương thức chuyển dịch như sau:

- PTCD 1: YTDH "koto"được chuyển dịch bằng một YTDH tuoong đưong trong tiếng Việt

(35) 岩田秀一が野々山の名を借りたこ とは明らかだ。(R: 175)

Việc Iwata Shuichi đã mượn tên của Nonoyama đã rõ.

(36) 彼を失ったことは痛い。(K: 370)

Việc mất đi anh ấy làm tôi đau đớn.

Trong các ví dụ trên đây, "koto" được chuyển dịch bằng YTDH tương đương trong tiếng Việt là "việc". "Việc" đóng vai trò danh hóa động từ và mệnh đề.

- PTCD 2: YTDH "koto"được chuyển dịch bằng một danh tù khái quát

(37) やることが多いとメモしておかな ければ志れてしまう。(R: 316)

Có quá nhiều việc phải làm, nếu không ghi lại gã sẽ quên mất.

(38) 目の前にあることが皆同じように 思えてくれる。(N: 157)

Người ta sẽ coi mọi thứ trước mắt mình đều nhất mực giống nhau.

Trong ví dụ (37), YTDH “koto" mặc dù được chuyển dịch bằng "việc", nhưng "việc" ở đây không đóng vai trò YTDH mà đóng vai trò là một danh từ khái quát. Vì trước "việc" có xuất hiện từ chỉ lượng "nhiều”. Còn ở ví dụ (38), "koto” được chuyển dịch bằng "thú " - danh từ khái quát chỉ phạm trù chung cho "sự vật, sự việc".

- PTCD 3: YTDH "koto" bi luoọc bỏ, trật tụ thành phần trong câu vẫn giũ nguyên nhu câu gốc tiếng Nhật. Tổ hơp "Động tì̀ + koto" được chuyển dịch bằng một danh tù phái sinh tù động tù xuất hiện trong tổ hợp đó.
(39) 彼の言うことは何もかもがもっとも だった。(R: 273)

Anh ta(Căn)/của/nói/ $\mathbf{\Delta / O / b a ̂ ́ t ~ c u ́ ~ c a ́ i ~}$ gi/O/chilý.

Mọi lâp luân Căn đưa ra đều chí lý.

(40) ルートが心配していることはすべ て正しいのだ。(H: 274)

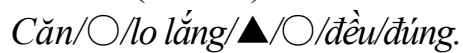

Mọi lo lắng của Căn đều chính xác.

Ở ví dụ (39), tổ hợp "nói + koto" và ở ví dụ (40) tổ hợp "lo lắng + koto" được thay thế bằng danh từ "lập luận", "lo lắng" khi chuyển dịch sang tiếng Việt. "lập luận" là danh từ có liên quan đến hoạt động nói năng. Mặc dù về mặt từ loại nó không có sự phái sinh trực tiếp nhưng nó có hàm ý biểu thị nội dung của động từ xuất hiện trong tổ hợp kết hợp với "koto". Còn "lo lắng" là danh từ được phái sinh từ động từ "lo lắng”. Đây là sự chuyển loại trong nội bộ thực từ.

- PTCD 4: YTDH "koto" bi luợc bỏ, trật tụ thành phần trong câu chuyển dịch có sụ thay đổi hoặc vẫn giũ nguyên so với câu gốc tiếng Nhật

(41) 社会面の記事などは見出しだけ

目を通してさっとページをめく

ってしまうことが多い。(R: 82)

Xã họi/của/bài báo/O/tiêu đề/chil

xem qua/nhanh chóng/

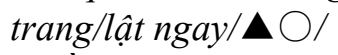
nhiều.

Thường thì khi xem báo hắn chỉ đọc lướt qua rồi lật ngay sang trang khác đối với các trang xã hội.

(42) 会員証の発見により、大きく一 方前進したことは確かだ。(R:147)

Thẻ họi viên/của/phát hiện/dụa vào/

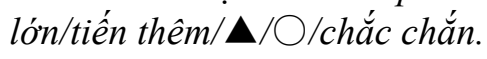

Rõ ràng là gã đã tiến thêm một bước dài nhờ tìm thấy tấm thẻ hội viên.

Trong các ví dụ trên, YTDH "koto” hoàn toàn bị lược bỏ khi chuyển dịch. Trật tự trong câu có sự thay đổi. Cụ thể là vị ngữ tính từ trong câu tiếng Nhật được chuyển lên đầu câu tiếng Việt. Đối với tính từ làm vị ngữ trong câu 
tiếng Nhật, trong quá trình khảo sát tôi thấy rằng có trường hợp tính từ được giữ nguyên, có
Bảng 11. Kết quả thống kê câu có vị ngữ là động từ có sử dụng “koto”

\begin{tabular}{|c|c|c|c|c|c|c|}
\hline \multicolumn{6}{|c|}{ Tên các tác phẩm truyện ngắn } & \multirow{2}{*}{ Tổng cộng } \\
\hline $\mathbf{R}$ & $\mathbf{H}$ & $\mathbf{K}$ & B & NP & $\mathbf{S}$ & \\
\hline $117(32,2 \%)$ & $49(13,5 \%)$ & $91(25,1 \%)$ & $43(11,8 \%)$ & $63(17,4 \%)$ & 28 & $391(100 \%)$ \\
\hline
\end{tabular}

trường hợp tính từ được chuyển sang một cách nói khác. Đây là phương thức chuyển dịch mà dịch giả chỉ quan tâm đến sự tương đương về nghĩa giữa hai câu khi dịch chứ không quan tâm đến sự tương đương của từng yếu tố. Ví dụ như ở câu (41), cụm " * koto ga ooi” khi chuyển dịch sang tiếng Việt, tính từ "ooi/ nhiều" đã bị mất đi, thay vào đó là phó từ "thường" để thay thế cho cụm tính từ nói trên. Hay đối với câu
Trong tổng số 391 câu vị ngữ động từ thu được trên đây có 08 câu bị lược bỏ động từ vị ngữ. Để xem xét những động từ vị ngữ nào đi với “koto", tôi tham khảo cách phân loại động từ của Kudo (1985) và đã thống kê được thành các nhóm như trong bảng dưới đây:

Bảng 12. Bảng phân loại nhóm động từ được dùng trong câu có vị ngữ là động từ có sử dụng "koto"

\begin{tabular}{|c|c|c|c|}
\hline STT & Nhóm động từ & Ví dụ & Số câu \\
\hline 1 & $\begin{array}{l}\text { Nhóm động từ chỉ các hoạt động liên quan đến tri } \\
\text { giác, giác quan }\end{array}$ & $\begin{array}{l}\text { 見る/nhin, xem } \\
\text { 聞く/nghe... }\end{array}$ & $11(2,8 \%)$ \\
\hline 2 & $\begin{array}{l}\text { Nhóm động từ chỉ các hoạt động có tính tác động } \\
\text { của con người }\end{array}$ & $\begin{array}{c}\text { する/làm } \\
\text { 調べる/ điều tra... }\end{array}$ & $90(23,0 \%)$ \\
\hline 3 & $\begin{array}{l}\text { Nhóm động từ liên quan đến hoạt động tư duy của } \\
\text { con người }\end{array}$ & $\begin{array}{c}\text { 分る/hiểu, 考える/ } \\
n g h i \text {... }\end{array}$ & $59(15,0 \%)$ \\
\hline 4 & $\begin{array}{l}\text { Nhóm động từ biểu thị các hoạt động liên quan đến } \\
\text { hoạt động truyền đạt thông tin }\end{array}$ & $\begin{array}{l}\text { 言う/nói } \\
\text { 知らせる/thông báo... }\end{array}$ & $31(7.9 \%)$ \\
\hline 5 & Nhóm động từ thể hiện các hoạt động biểu thị ý chí & 決める/quyết định.... & $50(12,7 \%)$ \\
\hline 6 & $\begin{array}{l}\text { Nhóm động từ thể hiện hoạt động tâm lý, yêu ghét... } \\
\text { của con người }\end{array}$ & $\begin{array}{c}\text { 嫌がる/ghét, 愛する/ } \\
\text { yêu... }\end{array}$ & $10(2,56 \%)$ \\
\hline 7 & Nhóm động từ biểu thị sự tồn tại, xuất hiện, tiêu biến & あるんる/có, ở... & $64(16,3 \%)$ \\
\hline 8 & Nhóm động từ chỉ các hoạt động biểu thị & 意味する/có ýnghĩa... & $2(0,5 \%)$ \\
\hline 9 & Nhóm động từ biểu thị sự biến đổi, thay đổi & $\begin{array}{c}\text { なる/trở nên, 変わる/ } \\
\text { thay dồi... } \\
\end{array}$ & $14(3,5 \%)$ \\
\hline 10 & Nhóm động từ biểu thị hoạt động tri nhận & 気づく/ nhận ra... & $47(12,0 \%)$ \\
\hline 11 & Nhóm động từ biểu thị hoạt động đánh giá & 驚く/ ngạc nhiên... & $6(1,53 \%)$ \\
\hline 12 & Nhóm động từ biểu thị khả năng & あり得る/ có thế... & $7(1,79 \%)$ \\
\hline \multicolumn{3}{|c|}{ Tổng cộng } & $391(100 \%)$ \\
\hline
\end{tabular}

(42), tính từ "Tashika/ rõ ràng, chắc chắn" lại được chuyển thành động từ "thùa nhận".

\subsubsection{Cách chuyển dịch "koto" trong câu có} vị ngũ là động tù

Đối với câu có vị ngữ là động từ, tôi thu được kết quả thống kê như sau:
Theo kết quả ở bảng 12 trên đây, ta thấy nhóm động từ được dùng nhiều nhất là động từ chỉ hoạt động tác động của con người ( $23 \%)$, tiếp đến là nhóm động từ thể hiện các hoạt động tồn tại, xuất hiện $(16,3 \%)$, nhóm động từ được sử dụng ít nhất là nhóm động từ 
liên quan đến hoạt động biểu thị $(0,5 \%)$. Các động từ biểu thị các hoạt động liên quan đến tri giác, giác quan của con người có tỉ lệ sử dụng ít hơn so với câu có vị ngữ động từ được danh hóa bằng yếu tố "no".

Trong các ví dụ trên, YTDH "koto” được chuyển dịch bằng YTDH tương đương trong tiếng Việt là "việc". "Việc" có vai trò danh hóa động từ và mệnh đề, nó có chức năng tạo ra các tổ hợp danh từ tính. Theo kết quả thống kê, phương thức chuyển dịch này xuất hiện không nhiều, chỉ có 07 câu trong tổng số 194 câu.

- PTCD 2: Yếu tố danh hóa "koto"được chuyển dịch bằng một danh tù khái quát

Theo phương thức chuyển dịch 2 , kết quả thu được như sau:

Bảng 13. Danh từ khái quát chuyển dịch "koto" trong câu có vị ngũ là động từ một danh từ khái quát như: điều, việc,... Động từ và mệnh đề đứng sau chúng có vai trò như một định ngữ, hay mệnh đề định ngữ. "việc" được dùng ở đây không phải với vai trò YTDH như trong phương thức chuyển dịch 1 , mà đóng vai trò là một danh từ khái quát. Lý do là ở ví dụ (44), giữa "việc" và động từ "nghe" có dùng từ tình thái "có thể".

- PTCD 3: Tổ hơp " động tù + koto" được chuyển dịch bằng một danh tù. Danh tù này được phái sinh tù động tù xuất hiện trong tổ hơp đó.

(45) 女房の姪ごさんがなくなったことを たまたま思い出してしまった。(R: 65)

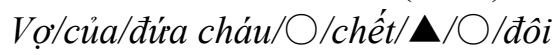
khi/ nhó lại.

Chẳng qua cậu nhớ lại cái chết của cô cháu vợ mà thôi.

\begin{tabular}{|c|c|c|c|c|c|}
\hline $\begin{array}{c}\mathbf{R} \\
\text { (2 câu) }\end{array}$ & $\begin{array}{c}\text { H } \\
\text { (8 câu) }\end{array}$ & $\begin{array}{c}\mathbf{K} \\
\text { (10 câu) }\end{array}$ & $\begin{array}{c}\text { B } \\
(5 \text { câu })\end{array}$ & $\begin{array}{c}\text { NP } \\
(5 \text { câu) }\end{array}$ & $\begin{array}{c}\mathbf{S} \\
(0 \text { câu })\end{array}$ \\
\hline điều (2) & $\begin{array}{c}\text { điều (4), chuyện, } \\
\text { việc (3) }\end{array}$ & $\begin{array}{c}\text { diều (2), chuyện (2), } \\
\text { việc (3), thứ, nhüng gi, } \\
\text { sưv viẹcc }\end{array}$ & $\begin{array}{l}\text { diều, việc, ý } \\
\text { dịnh, khi (2), }\end{array}$ & $\begin{array}{l}\text { diè̀u (2), nhũ̃ng gì } \\
\text { (2), sụ việc }\end{array}$ & \\
\hline
\end{tabular}

Trong số 06 tác phẩm thu thập ngữ liệu thì tác phẩm "K (Kitchen)" có số lượng câu có YTDH "koto" được chuyển dịch bằng một danh từ khái quát là nhiều nhất (10 câu). Trong khi đó tác phẩm "R (Ring)" có số lượng câu vị ngữ động từ nhiều nhất (117 câu) thì lại chỉ có 02 câu được chuyển dịch theo phương thức này.

（43）浅川は昨日分ったことをうまく整理 して、時間の経過に従って並べていっ た。(R: 396)

Asakawa cẩn thận sắp xếp những điều mà gã tìm được trong ngày hôm qua và trình bày theo thứ tự thời gian.

(44) ラジオで野球中継が聞けることさ えつい最近分ったくらいだから。(

Ngay cả việc có thể nghe tường thuật trực tiếp trên đài cũng là chuyện mới đây ông mới biết.

Ở các ví dụ trên, YTDH trong câu tiếng Nhật được chuyển dịch sang tiếng Việt bằng
（46）猫を捨てながら、彼は母親の言 つたことを思った。(B: 115)

Con mèo/O/vút bỏ/vùra/anh ta/O/

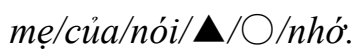

Anh nhớ lại lời mẹ trong lúc vứt con mèo đi.

Ví dụ (45), (46) cho thấy tổ hợp " động từ + koto" được chuyển dịch bằng một danh từ. Danh từ này thường là danh từ phái sinh từ động từ xuất hiện trong tổ hợp. Cụ thể ở ví dụ (45), tổ hợp " chết + koto" được chuyển dịch bằng danh từ "cái chết", ở ví dụ (46) tổ hợp " nói + koto" được chuyển dịch bằng danh từ "lờ nói".

- PTCD 4: YTDH bị luợc bỏ. Trật tư thành phần trong câu có sụ thay đổi theo trật tụ thành phần câu trong tiếng Việt.

(47)恐怖があることを知っている。(R: 14) Sự sợ hãi/O/có/A/O/biết. biết có một nỗi sợ. 
Ngoài các phương thức chuyển dịch đã đề cập trên đây, kết quả khảo sát cho thấy có rất nhiều câu được dùng với cấu trúc “そう いうこと/ chuyện nhu thế...”, “こういうこ と/ chuyện nhu này...”. Những cấu trúc này có dùng từ chỉ thị “そう” hay “こう” kết hợp với động từ “いう” và đi với “こと”. Tất cả những cấu trúc này đều được chuyển dịch theo cách coi tổ hợp trên đây là một cụm từ cố định và thường được chuyển dịch thành: "chuyện đó", "chuyện này" "chuyện ấy" "sụ việc ấy”... Ví dụ:

(48) そういうことを結構炎々とぼんや り考えていた。(K:76) trong tiếng Việt

(49) 博士の記憶の仕組みを把握する ことだった。(H: 62)

Câu chuyển dịch: Nhưng khó khăn nhất vẫn là việc nắm bắt cơ chế ghi nhớ của giáo sư.

- PTCD 2: YTDH "koto" được chuyển dịch bằng môt danh tù khái quát

Các danh từ khái quát trong tiếng Việt được dùng để thay thế khi chuyển dịch "koto" cụ thể như sau:

Bảng 15. Danh từ để chuyển dịch "koto" trong trường hợp "koto" nằm trong tổ hợp "động từ + koto" làm vị ngữ trong câu

\begin{tabular}{|c|c|c|c|c|c|}
\hline $\mathbf{R}$ & $\mathbf{H}$ & $\mathbf{K}$ & $\mathbf{B}$ & $\mathbf{N P}$ & $\mathbf{S}$ \\
\hline $\begin{array}{c}\text { (3 câu) } \\
\text { chuyện, điều, việc }\end{array}$ & $\begin{array}{c}\text { (1 câu) } \\
\text { diè̀u }\end{array}$ & $\begin{array}{c}\text { (2 câu) } \\
\text { chuyện (2) }\end{array}$ & $\begin{array}{c}\text { (1 câu) } \\
\text { diều }\end{array}$ & $\begin{array}{c}\text { (2 câu) } \\
\text { chuyện (2) }\end{array}$ & (0 câu) \\
\hline
\end{tabular}

Tôi đã suy nghĩ về những chuvên đó một cách khá bình thản và mơ hồ.

\subsubsection{Cách chuyển dịch tổ hợp "Động tù̀)} tính tì̀ + koto" làm vị ngũ trong câu

Đây là những trường hợp "koto" nằm ở vị trí vị ngữ chính trong câu. Thành phần kết hợp phía sau "koto" có thể là trợ động từ "dearu" được chia ở các dạng như thời hiện tại (dearu/ $d a)$, thời quá khứ (datta), phủ định (dewanai), phỏng đoán (deshou, dearouka), trợ từ cuối câu $(y o, n e)$, trợ từ nghi vấn $(k a) \ldots$ Kết quả khảo sát thu được như sau:

Bảng 14. Kết quả thống kê các trường hợp "koto" nằm trong tổ hợp "động từ/ tính từ + koto" làm vị ngữ trong câu
Xét các ví dụ sau đây:

(50) オマジナイの中身、簡単じゃ ないか、誰にでもできることだ。(R: 928) Nội dung của câu thần chú chẳng phải là rất đơn giản hay sao? Một việc mà ai cũng làm được.

(51) 兄と恋人を一度に亡くすこと はそうあることではない。

(K: 350)

Cả anh trai và bạn gái cùng lúc không còn trên cõi đời này nữa đâu phải là một chuyện thường xảy ra.

Ở các ví dụ trên đây, YTDH "koto" được chuyển dịch bằng một trong các danh từ khái quát: "việc”, “chuyện”, "điều”. Ở ví dụ (50), "viẹcc" không đóng vai trò của một YTDH như ở phương thức chuyển dịch 1 mà đóng

\begin{tabular}{|c|c|c|c|c|c|c|}
\hline \multicolumn{5}{|c|}{ Tên các tác phẩm truyện ngắn } & \multirow{2}{*}{ Tổng cộng } \\
\hline $\mathbf{R}$ & $\mathbf{H}$ & $\mathbf{K}$ & $\mathbf{B}$ & $\mathbf{N P}$ & $\mathbf{S}$ & \\
\hline $31(29,2 \%)$ & $25(23,5 \%)$ & $26(24,5 \%)$ & $7(6,6 \%)$ & $12(11,3 \%)$ & $5(4,7 \%)$ & $\mathbf{1 0 6}(\mathbf{1 0 0 \% )}$ \\
\hline
\end{tabular}

Trong những trường hợp này, "koto" có các phương thức chuyển dịch như sau:

- PTCD 1: YTDH "koto" được chuyển dịch bằng một YTDH tương đương vai trò như một danh từ khái quát, vì trước "viẹc" có sử dụng lượng từ " $m o ̂ t ~ t$ " và giữa tổ hợp "việc + mệnh đề" có chen thêm từ “mà". Với những dấu hiệu trên, tôi khẳng 
định "việc" ở đây không phải là YTDH mà là danh từ khái quát biểu thị "việc, chuyện cần phải làm”. Ở các ví dụ (51) “chuyện" đóng vai trò là danh từ khái quát có ý nghĩa như "sự việc", "vấn đề".

- PTCD 3: Khi thành phần kết hợp trước "koto" là tổ hợp "đại tù nghi vấn + Iu" thì vai trò YTDH của "koto" không còn nũa mà nó cùng với tổ hợp đứng trước tạo nên một cụm danh tù cố định.

(52) 一体どういうことなのか。

\section{Rốt cuộc chuvên gì đang xảy ra?}

Trong quá trình khảo dữ liệu, tôi thấy tổ hợp đứng trước “koto” thường gặp ở đây là “đại từ nghi vấn $D o u+i u$ ”. Bản thân đại từ nghi vấn "Dou" có ý nghĩa là "như thế nào" nhưng khi kết hợp với cụm " iu koto" thì lại được chuyển dịch thành nhiều cách nói khác nhau, như: "nhu thế nào", "nghĩa là gì", "chuyện gì”...

- PTCD 4: YTDH "koto" bi luợc bỏ đi. Trật tự thành phần trong câu không bị thay đổi.

(53) 48歳で自殺して死んだこと。

Tuổi 48/ở/tụ sát/chết/

Ông ta tự sát và chết ở tuổi 48.

Ta thấy ở ví dụ (54) YTDH "koto" đóng vai trò danh hóa cho động từ và mệnh đề khi chuyển dịch sang tiếng Việt đã bị lược bỏ.

- PTCD 5: Tổ hơp "Động tù + koto" được chuyển dịch bằng một danh tù thuoòng là được chuyển loại tù động tù xuất hiện trong tổ hơp đó

(54) それはちやんと考えて決めたこと

だ。 $(\mathrm{K}: 57)$

Đó là/o/cẩn thận/suy nghĩ/quyết định/A.

Đó là một quyết định hoàn toàn có suy nghĩ chín chắn.

Ở ví dụ (54), tổ hợp "quyết định (động từ) + koto" trong câu gốc tiếng Nhật được chuyển dịch không phải bằng một tổ hợp "YTDH+ động từ" tương đương trong tiếng Việt mà được dịch bằng danh từ "quyết định" được chuyển loại từ động từ “quyết định". Đây là kiểu chuyển loại có hình thức đồng âm (Diệp Quang Ban, 1991: 154), nghĩa là một từ thuộc từ loại này khi chuyển thành một từ thuộc từ loại khác vẫn giữ nguyên vỏ ngữ âm.

\section{Kết luận}

Khi đối chiếu cách chuyển dịch các YTDH "no" và "koto" trong tiếng Nhật sang tiếng Việt qua các bản dịch tác phẩm truyện ngắn, kết quả khảo sát thu được như sau:

- Khác với tiếng Nhật, khi chuyển dịch sang tiếng Việt, đối với trường hợp danh hóa động từ, thì cả câu có vị ngữ danh từ, vị ngữ tính từ, vị ngữ động từ đều có những phương thức chuyển dịch giống nhau. Đó là:

(i) YTDH trong tiếng Nhật được chuyển dịch bằng một $\mathrm{YTDH}$ tương đương trong tiếng Việt.

(ii) YTDH trong tiếng Nhật được chuyển dịch bằng một danh từ khái quát. (iii) Tổ hợp “ Dộng tù + yếu tố danh hóa" trong câu tiếng Nhật được chuyển dịch bằng một danh từ. Danh từ này thường được phái sinh từ động từ xuất hiện trong tổ hợp đó.

(iv) YTDH trong tiếng Nhật bị lược bỏ khi chuyển dịch.

Trong các phương thức chuyển dịch trên đây thì phương thức chuyển dịch (i) được sử dụng ít nhất. Tiếp đến là các phương thức chuyển dịch (ii) và(iii). Phương thức chuyển dịch (iv) được sử dụng nhiều nhất.

- Các YTDH“no" và "koto" khi được chuyển dịch bằng một YTDH tương đương trong tiếng Việt thì YTDH được chọn đều là "việc", không thấy có sự xuất hiện của các YTDH nào khác.

- Trường hợp YTDH trong tiếng Nhật được chuyển dịch bằng một danh từ khái quát thì cả "no" và "koto" đều được chuyển dịch bằng những danh từ khái quát chung. Tuy nhiên, khi so sánh hai YTDH này thì có thể thấy số lượng câu có sử dụng "no" được chuyển dịch bằng danh từ khái quát nhiều hơn và chủng loại danh từ cũng 
đa dạng và phong phú hơn so với câu có sử dụng YTDH "koto". Khi chuyển dịch cả hai YTDH "no" và "koto" sang tiếng Việt, trật tự thành phần câu có 2 khả năng xảy ra: đó là được giữ nguyên hoặc bị thay đổi cho phù hợp với trật tự thành phần câu trong tiếng Việt. Kết quả thống kê cho thấy, yếu tố danh hóa "No" được sử dụng nhiều hơn so với yếu tố danh hóa "Koto". Điều này chứng tỏ rằng phạm vi sử dụng của yếu tố danh hóa "No" rộng hơn so với yếu tố danh hóa "Koto".

Như vậy, kết quả nghiên cứu đối chiếu và khảo sát các YTDH trong tiếng Nhật với các YTDH và cách diễn đạt tương đương trong tiếng Việt trên đây có giá trị ứng dụng vào việc giảng dạy tiếng Nhật như một ngoại ngữ và biên soạn giáo trình dành cho đối tượng người học là người Việt Nam. Đối với việc giảng dạy tiếng Nhật như một ngoại ngũ̃, kết quả nghiên cứu có thể ứng dụng vào giảng dạy những môn liên quan đến thực hành dịch. Hiện nay, việc giảng dạy và học ngoại ngữ ở nước ta được quan tâm và đầu tư khá nhiều. Mô hình đào tạo tín chỉ cũng đã phát huy được tính ưu việt của nó khi người học đã trở thành trung tâm của quá trình đào tạo. Tuy nhiên, việc dạy và học vẫn còn mang nặng tính lý thuyết, việc thiết kế chương trình đào tạo đã có nhiều cải tiến nhưng dường như vẫn chưa theo kịp với xu thế phát triển của xã hội. Việc giảng dạy và học môn dịch cũng không phải là ngoại lệ. Để khắc phục những khó khăn và trở ngại liên quan đến việc nắm bắt cách dùng hai YTDH “no", "koto" thì kết quả đối chiếu trên đây sẽ là một tài liệu có giá trị để tham khảo cho việc giảng dạy các môn thực hành dịch. Cụ thể là khi gặp những câu có sử dụng YTDH “no", "koto”, người dạy có thể thiết kế bài giảng bằng việc trích dẫn những câu ví dụ có sử dụng "no" và "koto" trong 06 tác phẩm truyện ngắn được khảo sát. Khi thực hiện bài giảng, trước hết nên cho người học tự đưa ra cách dịch của mình trước, sau đó người dạy sẽ nhận xét và đưa ra các phương thức dịch khác nhau. Như vậy, người học mới nhận thấy rằng không chỉ có một cách dịch mà tuỳ thuộc vào từng ngôn cảnh còn có rất nhiều cách dịch khác nhau, qua đó có thể giúp cho người học không bị mắc lỗi và sử dụng ngôn ngữ có hiệu quả hơn.

\section{Tài liệu tham khảo}

\section{Tiếng Việt}

Diệp Quang Ban (1991). Ngũ pháp tiếng Việt, tập 1. Hà Nội: NXB Giáo dục.

Nguyễn Thị Lương (2006). Câu tiếng Việt. Hà Nội: NXB Đại học Sư phạm.

Nguyễn Kim Thản (1991). Co sở ngũ pháp tiếng Việt. TP. Hồ Chí Minh: NXB Hồ Chí Minh.

Lý Toàn Thắng (1997). Loại từ và các tiểu loại danh từ trong tiếng Việt. T/c Ngôn ngũu, số 2.

Nguyễn Thị Thuận (2002). Danh hóa trong tiếng Việt hiện đại. Luận án tiến sỹ ngữ văn, Trường Đại học Khoa học Xã hội và Nhân văn - Đại học Quốc gia Hà Nội.

\section{Tiếng Nhật}

市川保子 (1997) 『日本語誤用辞典』、ISEBU出版. (Ichikawa Yasuko (1997). Tù điển lồi sai của ngườt học tiếng Nhạt, NXB Isebu.)

大島資生(1996)「補文構造にあらわれる「こと」 「の」について」『東京大学留学生センター 紀要』、6号、p.47-68.

(Ojma Motoo (1996). Bàn về 「NO」và 「KOTO」 xuất hiện trong cấu trúc câu ghép. Kỷ yếu Trung tâm lưu học sinh trường Đại học Tokyo, số 6, tr.47- 68.)

鎌田倫子 (1998)「コトとノの選択規則」『日本語 教育』、98号、日本語教育学会、p.1-12.

(Kamada Tomoko (1998). Quy tắc lựa chọn No và Koto. T/c Japanese Journal of Educational Psychology, NXB Hiệp hội giảng dạy tiếng Nhật, tr.1-12.)

工藤真由美(1985)「の、ことの使い分けと動詞の 分類」『国文学解勫の鑑賞』、3月号、至文 堂、p.45-52.

(Kudo Mayumi (1985). Cách dùng của $\lceil\mathrm{NO}\rfloor$, $\lceil\mathrm{KOTO}\rfloor$ và phân loại động từ. T/c Tìm hiểu và thuởng thức quốc văn học Nhật Bản, số 3, NXB Shibundo, tr.45-52.)

田中望(1997)『日本語文法』、凡人社.

(Tanaka (1997). Ngũ pháp tiếng Nhật. NXB Bonjinsha.) 


\title{
THE METHODS OF TRANSLATING VERB- NOMINALIZING AFFIXES FROM JAPANESE INTO VIETNAMESE
}

\author{
Tran Thi Minh Phuong \\ Faculty of Japanese Language and Culture, VNU University and Languages and International \\ Studies, Pham Van Dong, Cau Giay, Hanoi, Vietnam
}

\begin{abstract}
This article discusses the methods of translating verb-nominalizing affixes from Japanese into Vietnamese. The result of our survey of data from 06 Vietnamese versions of Japanese short stories indicates that several translation methods have been consistently applied to all nouns, adjectives and verbs as predicators involving verb-nominalization. To be more specific, these include: (i) the nominalizing affix in Japanese is translated as an equivalent one in Vietnamese; (ii) the nominalizing affix in Japanese is translated as a generic noun; (iii) the combination "verb + nominalizing affix" in Japanese sentences is translated as a noun which is derived from a verb in that combination; and finally, (iv) the nominalizing affix is left out in the translating process. All these methods of translation can be arranged in the following order from the least to the most common: (i), (ii), (iii) and (iv). Besides, when the nominalizing affixes are rendered with their equivalents in Vietnamese, no other lexemes are chosen apart from "việc", a common nominal indicator that accompanies verbs.
\end{abstract}

Keywords: nominalizing affix, "No", "Koto", method of translation 